\title{
AS CONSTANTES MIGRAÇÕES NOS CONCEITOS DE LEITOR/AUTOR NA POESIA DE PAULO LEMINSKI
}

\author{
THE CONSTANT MIGRATIONS IN THE CONCEPTS OF READER/AUTHOR IN \\ THE POETRY OF PAULO LEMINSKI
}

\author{
Gutemberg Alves Geraldes Junior ${ }^{1}$
}

\begin{abstract}
RESUMO: Esta pesquisa busca discutir e analisar o lugar do leitor e suas migrações na obra poética de Paulo Leminski. Para tanto, problematizou-se o processo de construção do poeta, a relação migratória entre o leitor e o poeta (e vice-versa) e de suas identidades nos contornos do pensamento do autor de Catatau. Por isso, a pesquisa é apoiada nos pressupostos teóricos da percepção do leitor como um elemento de construção textual, partindo do conceito de Leitor-Modelo apresentado por Umberto Eco. Com esta base teórico-metodológica é possível identificar na poesia de Leminski uma preocupação constante em proporcionar ao leitor elementos que facilitem a sua compreensão do texto, pistas que o façam construir um sentido do texto e lacunas que se completem por meio de seus leitores, promovendo uma migração no conceito de autoria e deslocando o conceito de autor como uma entidade singular, fixa. Os resultados alcançados ratificam a hipótese de que, sabedor da condição de autor que o leitor assume ao cooperar com um poema, a obra de Paulo Leminski traz elementos capazes de revelar a posição de poeta do leitor por meio de estratégias textuais que estão sempre aptas a criar conexões entre a obra, o autor e seu leitor.
\end{abstract}

\section{Palavras-chave: Migração. Autor. Leitor.}

ABSTRACT: This research seeks to discuss and analyze the place of the reader and his migrations in the poetry of Paulo Leminski. For this, the process of construction of the poet, the migratory relation between the reader and the poet, and their identities in the contours of the author's thought of Catatau were problematized. Therefore, the research is supported by the theoretical assumptions of the reader's perception as an element of textual construction, starting from the concept of Reader-Model presented by Umberto Eco. With this theoretical-methodological basis it is possible to identify in the poetry of Leminski a constant concern in provide the reader with elements that facilitate his understanding of the text, clues that make him construct a sense of the text and gaps that are completed through his readers, promoting a migration in the concept of authorship and displacing the concept of author as a singular entity, fixed. The results obtained ratify the hypothesis that, knowing the author status that the reader assumes when cooperating with a poem, the work of Paulo Leminski brings elements capable of revealing the position of poet of the reader through textual strategies that are always apt to create connections between the work, the author and its reader.

Keywords: Migration. Author. Reader.

\section{INTRODUÇÃO}

Emir Rodríguez Monegal (1980) traz à luz um conceito interessante e significativo em seu estudo sobre a obra do poeta argentino Jorge Luis Borges, do qual tomo emprestado por entender que este conceito evidencia uma fortuna extremamente profunda em relação ao ato de ler poesia. Quando o escritor argentino evidencia, já no título de sua obra, o termo "poética da

\footnotetext{
I Publicitário, Doutor em Ciências da Linguagem, coordenador do curso de Publicidade e Propaganda da Faculdade Satc, onde também atua como professor e pesquisador do Grupo de Estudos em Comunicação e Design-GECED.gutembergeraldes@satc.edu.br.
} 
leitura”, Monegal (1980) atém-se à relação sempre evidente, mas pouco estudada quando o assunto é poesia, entre receptor e obra. Em linhas gerais, a lição de Borges propõe nulificar as pretensões de paternidade literária, uma vez que o ato de produção não se restringe à escrita, mas também ocorre durante a leitura.

Monegal (1980) nos mostra ainda que a obra pertence também ao leitor que, ao exercer a atividade de leitura, sempre confere significado e originalidade ao texto. Isso realça a ideia de que a linguagem é de todos, bem como promove o leitor à condição de autor e, com isso, evidencia o problema desta pesquisa: como as constantes migrações nos conceitos de leitor/autor são evidenciadas na poesia de Paulo Leminski?

Dessa forma, este artigo, fruto de uma pesquisa anterior deste autor, objetiva promover uma discussão acerca das constantes migrações no conceito de leitor/autor trazidas pela poesia de Paulo Leminski. Assim, justifica-se por discutir um assunto que, embora muito discutido, ainda está longe de se chegar em uma definição cabal. Este artigo justifica-se também por mostrar que a migração, tão em voga em nossos telejornais e feeds de notícias atuais, não é uma questão exclusiva do universo teórico do campo político/geográfico, mas sim, cultural. E, por isso, está sempre em evolução, como o organismo vivo que é. Constituindo-se assim como uma espécie de poética de leitura. Por isso, é importante que metodologicamente, este trabalho tenha um cunho qualitativo descritivo, com a intenção de confrontar autores e tentar extrair deste confronto as principais ideias para que possamos chegar em um elemento visível da migração dos conceitos propostos na poesia do autor de Catatau.

Desta forma, ao trazer para o centro da discussão o termo "poética da leitura" primeiramente cunhado por Monegal (1980), evidencia-se a subdivisão desse termo em dois entendimentos: (a) ferramentas que o poeta utiliza para materializar o lugar do leitor no próprio poema $\mathrm{e}(\mathrm{b})$ as pistas ou índices que proporcionarão um caminho à leitura, uma vez que a própria poesia, como diria Waly Salomão em seu poema Devenir, Devir, "Não acaba com o ponto final" (SALOMÃO, 20oo, p. 46) e a obra, aberta, sempre oferece contínua predisposição à produção posterior e sempre renovadora daquele que a lê.

A poética da leitura em Paulo Leminski como elemento de migração

Faz-se relevante, para se tratar do termo grafado por Monegal (1980), discutirmos um local que é mais uma estrada de pedras do que asfáltica em uma clara alusão aos poemas de $\mathrm{A}$ educação pela pedra, de João Cabral de Melo Neto (2008). O local da leitura é sempre um ambiente polêmico e, por isso mesmo, esta pesquisa deve clarificar qual o escopo teórico que se desenhará a partir deste momento.

Dessa forma, vale lembrar que Aristóteles referia-se ao conceito grego de poiêtikê technê, 
conforme nos mostra Emil Staiger (1997), como uma forma de ensinar a essência da poesia, oferecer instruções práticas e modelos a iniciantes sobre a composição da poesia, por isso "deveria inventariar todos os modelos existentes, algo que gera o conhecido problema dos gêneros que, até então, na poética aristotélica, dividiam-se em superior (poesia épica e tragédia) e em inferior (comédia)" (BARROS, 2oio, p. 26).

O próprio Staiger (1997) vai apontar que o termo technê, vai desaparecer e dar à poética uma percepção antes renegada, ou seja, o fato de a poética deixar de ser precedida pela technê, vai oferecer ao termo a possibilidade de deixar de ser imitação da natureza e, sobretudo, de modelos de autores anteriores, clássicos, passando a ser compreendida como um exercício constante da criação. Não há como negar, dessa forma, a raiz do termo, também grego, poiésis, que expressa a ideia, segundo Barros (2010, p. 26) de "formação, criação, realização".

Em Conceitos fundamentais da poética, Staiger (1997) afirma que não reconhece gênero como modelo e despreza a tripartição dos gêneros, uma vez que "toda obra poética participa em maior ou menor escala de todos os gêneros e apenas em função de sua maior ou menor participação, designamo-la lírica, épica ou dramática” (STAIGER, 1997, p. 190). Sendo assim, pode-se perceber que cada obra participa de cada um dos três gêneros, sempre oscilando entre eles, porque a poética, de acordo com Staiger (1997, p. 197) “esforça-se para prover como a essência do homem aparece nos domínios da criação poética”. Ou seja, em uma percepção mais contemporânea, a poética se ocupa do que é arte, afinal o homem é um híbrido entre lírico, épico e dramático e é justamente essa característica multifacetada do homem que faz refletir-se sobre o fazer poético.

Hans Robert Jauss figura entre os pesquisadores que marcaram e contribuíram para os estudos literários contemporâneos, sobretudo, a partir de sua proposta de diálogo com o leitor que, para Jauss (1979), por meio da leitura firma uma verdadeira relação dialógica com texto. Com isso, Jauss insiste particularmente, como nos mostra Jimenez, "no papel primordial da reação dos leitores, de seus julgamentos e de suas expectativas diante de obras novas” (I999, p. 363).

Nesse sentido, pode-se observar que a obra literária passa a ser definida pela relação que se estabelece entre 'literatura e leitor', e Jauss de maneira alguma nega que “a relação entre literatura e leitor possui implicações tanto estéticas quanto históricas” (1979, p. 23). No que diz respeito às “implicações históricas”, o crítico alemão evidencia, como nos mostra Oliveira (2010), que ela se define pela síntese de experiências das leituras realizadas, a saber: (a) a primeira é obtida pela leitura e análise que o leitor faz da obra e outras que fizera em momentos anteriores, remetendo-nos a pensar que toda leitura já é em si comparada; (b) a segunda se dá pela bagagem de mundo que o leitor possui ou supõe ter adquirido ao longo de sua existência e o caráter histórico presente na essência da obra. O que é importante notar é que a leitura se concretiza na entidade 
leitor e que, para Barros (2010), é um elemento integrante da estética literária e essencial à constituição do sentido da obra, pois cabe a ele a percepção e atualização do fenômeno estético.

Outro teórico da Recepção Estética, Wolfgang Iser (1996), prefere trazer à luz a teoria do efeito estético, que se baseia no texto cuja decorrência somente é produzida no processo de leitura. Iser (I996, p. 83) afirma que "no ato de leitura, há a interação entre texto e leitor, e deste último exigem-se atividades imaginativas e perceptivas". Sendo assim, completa o filósofo alemão (1996), observa-se que pensar a leitura é pensar o efeito estético. Para corroborar esse pensamento, basta voltar os olhos ao conceito aristotélico de catarse (do grego kathársis, purificação, purgação) que já anunciava o efeito da arte em seu receptor.

Em seu Os limites da interpretação, Umberto Eco (2010) vai apontar que as mais diversas teorias que se ocupam do leitor vão ressaltar a importância do ato de leitura para a construção ou desconstrução - do texto; e isso vale tanto para a Estética da Recepção, quanto para a Hermenêutica, Semiótica e/ou Desconstrução. Para Eco (2010), cabe unicamente ao leitor atualizar e interpretar o texto; assim, pensar a leitura é, necessariamente, pensar a sua interpretação, isto é, somente exercendo o seu papel de leitor, o destinatário proporciona o funcionamento total do texto. De acordo com Eco, "um texto é um universo aberto em que o intérprete pode descobrir infinitas conexões" (2012b, p. 45).

Indo mais a fundo na relação entre o texto e o seu leitor, Eco (2012) destaca o conceito de tesouro social pelo qual ele torna evidente que a produção de um texto é dirigida a uma comunidade de leitores, cada um com sua competência em relação à língua. Para isto, ele afirma que:

Quando um texto é produzido não para um único destinatário, mas para uma
comunidade de leitores, o/a autor/a sabe que será interpretado/a não segundo
suas intenções, mas de acordo com uma complexa estratégia de interações que
também envolve os leitores, ao lado de sua competência na linguagem
enquanto tesouro social. Por tesouro social entendo não apenas uma
determinada língua enquanto conjunto de regras gramaticais, mas também
toda enciclopédia que as realizações daquela língua implementaram, ou seja, as
convenções culturais que uma língua produziu e a própria história das
interpretações anteriores de muitos textos, compreendendo o texto que o leitor
está lendo. (ECO, 2orab, p. 8o).

Com isso, pode-se perceber que o ato de ler é, em si mesmo, uma transação difícil entre a competência do leitor e o tipo de competência que um determinado texto "postula a fim de ser lido de forma econômica" (ECO, 2012b, p. 80). Conforme Barros (2010, p.31), "a economia de leitura [...] refere-se a não haver excessos e à possibilidade de um acordo entre uma comunidade de intérpretes".

Talvez por assumir uma postura 'marginal', Leminski tenha, em seu leitor, um elemento eclético e, por isso mesmo, trabalhe incansavelmente as multiplicidades significativas em sua 
fortuna poética. Ao tecer sua poética da leitura, o poeta curitibano oferece possibilidades interpretativas para os vários níveis de apreensão textuais. Seus poemas evidenciam um eu-lírico sempre atento ao leitor, um eu-lírico consciente de sua potencialidade intersemiótica e, sobretudo, um sujeito lírico que não se limita ao patamar de espelho do texto em uma via única da escrita, mas, principalmente, sugere ao leitor o modo como deseja ser lido. Por características como essas apresentadas e exploradas por Leminski ao longo de sua obra poética, esta pesquisa recorre a pressupostos teóricos fundamentadas no ato de leitura apresentadas por Eco, destaque para o seu conceito de leitor-modelo; também às ideias apresentadas por $\mathrm{Paz}$, destaque para o conceito de ananda, ou seja, deleite com o Uno - afinal, conforme nos diz $\mathrm{Paz}$ (2012, p. 33) "toda vez que o leitor revive de verdade o poema, atinge um estado que podemos chamar poético”.

Mesmo com foco voltado para as narrativas, os conceitos de Eco aplicam-se a todo tipo de textualidade, sobretudo ao lírico e, como bem deixa claro Barros em sua tese de doutorado:

Embora Umberto Eco investigue apenas textos narrativos, a teoria que desenvolve toma o conceito semiótico de texto, podendo, portanto, ser aplicada a todo tipo textual, inclusive a textos não-literários e não-verbais (ECO, 2004). Além disso, a aplicação de uma teoria de narrativa ao texto lírico pode ser subsidiada pela definição de eu-lírico como "um enunciador fictício" e pelo conceito de cena do poema-lírico com "a ficção" que são oferecidos por Francis Achcar (1994)”. (BARROS, 2010, p. 27)

Sendo assim, Eco (2012a) utiliza-se das mais diversas ferramentas que vão desde o formalismo russo, do complexo sígnico de Roman Jakobson, da Semiótica de Charles S. Peirce, à Semiologia de Roland Barthes para enriquecer a sua proposta de estudo baseada na atividade cooperativa e interpretativa do leitor no texto. Ou seja, no cerne do universo ficcional está a leitura e, em consequência disso, como agente direto, o leitor. Eco (2012a, p. 42) postula que todo texto é um "universo aberto em que o intérprete (neste caso, o leitor) pode descobrir infinitas interconexões”. Ao visitar Alfonso Reyes, Paz (2012) mostra que prosa é o que está dito, já um texto lírico, poético, é o que está no não-dito, o que permite a todo leitor, em qualquer que seja o seu tempo, atualizar o conteúdo daquela obra, daquele poema. Talvez por estar antenado com esse pensamento, Leminski dê um papel importante para a cooperação sempre consciente e participativa do seu leitor para que o texto flua. Eco nos mostra que:

O texto está, pois, entremeado de espaços brancos, de interstícios a serem preenchidos, e quem o emitiu previa que esses espaços e interstícios seriam preenchidos e os deixou brancos por duas razões. Antes de tudo, valorização de sentido que o destinatário ali introduziu; [...] Em segundo lugar, porque, à medida que passa da função didática para a estética, o texto quer deixar ao leitor a iniciativa interpretativa, embora costume ser interpretado com uma margem suficiente de univocidade. Todo texto quer que alguém o ajude a funcionar. (ECO, 2012a, p. 37).

O que Eco explana e Leminski faz questão de trazer à tona em seus poemas é que cabe 
ao leitor preencher as possíveis lacunas deixadas em branco pelo texto. Essa consciência se apresenta tão iminente no poeta curitibano que já na epígrafe de seu livro de estreia Catatau, Leminski nos mostra o lugar ativo que o leitor terá no decorrer da obra ao afirmar que "me nego a ministrar clareiras para a inteligência deste catatau que, por oito anos, agora ${ }^{2}$, passou muito bem sem mapas. Virem-se." Esse pensamento leminskiano nos conduz ao encontro do pensamento de Umberto Eco no qual, explica Barros (2010), o leitor apresenta-se subdivido em dois tipos: (a) Leitor-Empírico, que "realiza uma leitura particular da obra com liberdade total" (BARROS, 20Io, p. 33); e (b) Leitor-Modelo, que se apresenta como um "leitor criado pela própria obra" (BARROS, 20Io, p.33) e, em consequência disto, se apresenta como "colaborador ativo para dar sentido à ela [obra]" (BARROS, 2010, p.33). O curioso é que o teórico italiano mostra que o Leitor-Empírico, extratextual, é convidado a seguir o segundo, implícito no texto, conforme nos mostra no excerto a seguir:

O Leitor-Modelo de uma história não é o leitor empírico. O leitor empírico é você, eu, todos nós, quando lemos um texto. Os leitores empíricos podem ler de várias formas, e não existe lei que determine como devem ler, porque em geral utilizam o texto como um receptáculo de suas próprias paixões, as quais podem ser exteriores ao texto ou provocadas pelo próprio texto. (ECO, 200I, p. I4)

De acordo com Márcia Regina Santos (1999, p.64), para Umberto Eco “o leitor é sempre postulado como um operador do texto porque é responsável por sua atualização”, conforme supracitado. Isto traz para o centro da discussão o fato de que "um texto é sempre incompleto diante do olhar do destinatário" (SANTOS, i999, p.64). Ou seja, segundo Santos, "enquanto o leitor não interage com o texto, este último continua sem voz ativa, fraco, preguiçoso, como nomeia o próprio Eco. E para que haja a atualização, o leitor precisa ser cooperativo, consciente e ativo no momento da leitura" (I999, p.7I). E é justamente este ambiente lúdico entre texto e leitor, este jogo de leituras possíveis, que vai encontrar reflexo na poesia de Paulo Leminski.

Atuando em um processo de leitura que vai além do superficial, surge, segundo Santos, o que “Eco trata como 'Não-dito', ou seja, o que está entremeado no texto. Para fazer partedeste processo, o leitor precisa efetuar uma série complexa de movimentos cooperativos, entre eles, a operação extensional e a inferencial” (I999, p. 72). Corroborando este pensamento, pode-se observar anteriormente que o texto postula a cooperação do leitor como condição própria de sua atualização. Sendo assim, Eco vai mostrar que um texto é "um produto cujo destino interpretativo deve fazer parte do seu próprio mecanismo generativo: gerar um texto significa atuar segundo uma estratégia que inclui as previsões dos movimentos do outro - tal como acontece em toda a estratégia." (2012b, p.57) Muito embora o Leitor-Modelo coopere ativamente para alcançar o

${ }^{2}$ Vide "Jornal do Escritor" (no 6, nov. de 1969, Rio de Janeiro, [s/p]), onde tiveram lugar o lançamento oficial da ideia, entrecho e amostragem das primeiras do Catatau. 
sentido do texto, este é guiado, segundo Eco por uma entidade chamada Autor-Modelo, que pode ser percebida como um estilo, mas sobretudo "como uma estratégia textual explícita" (2012b, p. 82) que, em consequência disso, vai revelar a intenção do texto. Isto é, ao tornarem-se evidentes no percurso da leitura, tanto o Leitor-Modelo, quanto o Autor-Modelo, são entidades que se criam mutuamente. Mas o que vale deixar evidente mesmo é que "entre a intenção inacessível do autor e a intenção discutível do leitor está a intenção transparente do texto, que invalida uma interpretação insustentável” (ECO, 2012b, p. 93). Torna-se evidente, então, que o texto norteia e instrui a participação do leitor e, conforme Barros (2010) desde o processo gerativo do texto, já estão previstas atitudes interpretativas do Leitor-Modelo.

Essa discussão traz à cena a possibilidade real de que Leminski, consciente de sua posição de poeta - ou melhor, de "útil operário do signo", eleva o eu-lírico de sua obra a uma consciência teórica onde o Leitor-Modelo possa reconhecê-lo e, sobretudo, notar todas as suas estratégias estilísticas; já que, para Eco (2012a), o Autor-Modelo antecipa algumas possibilidades de leitura. Embora seja evidente essa antecipação feita pelo Autor-Modelo, vale salientar que essa simples antecipação não nos fornece a possibilidade de previsão do resultado do diálogo interpretativo isto é função exclusiva do leitor, através daquilo que Décio Pignatari (1987) denominaria de 'repertório'. Portanto, gerar um texto significa executar uma estratégia de que fazem parte as previsões dos movimentos dos outros e, assim, contribuir para tornar a obra um produto cultural.

\section{Considerações Finais}

Esse pensamento conduz a um caminho de fruição estética, um caminho ao qual Eco (1976) vai condicionar a uma provável abertura. Afinal, afirma o teórico italiano, "Tôda [sic] forma fruível como dotada de valor estético é 'aberta"' (ECO, 1976, p. 89); logo, sublinha-se que o texto literário, tal qual o poema, é um discurso aberto permeado de ambiguidades em que o valor encontra-se também no seu processo de construção e, com isso, permissivo a um processo de migração onde o próprio leitor se torna um autor, devido as lacunas preenchidas por ele ao longo do texto.

Sendo assim, o leitor aparece como fruidor da obra que lhe foi ofertada, previamente, pelo autor e, por isso mesmo, assume uma função extremamente ativa na construção do texto, isto é, ele migra de posição no decorrer do corpus textual. No fundo, afirma Eco (1976, p. 40), “a forma torna- se estèticamente válida a medida em que pode ser vista e compreendida segundo multíplices perspectivas, manifestando riqueza de aspecto e ressonâncias, sem jamais deixar de ser ela própria”.

Esse pensamento, além de nos permitir a leitura de que a poética da obra aberta tende a promover no leitor atos de liberdade consciente, leva-nos ao encontro da poesia leminskiana 
enquanto promotora desses atos de liberdade.Rompendo fronteiras e, sobretudo, evidenciando os movimentos de migração entre os conceitos elencados.

\section{Referências}

BARROS, Nismária Alves David. O lugar do leitor na poesia de Manoel de Barros. 2010. $147 \mathrm{f}$. Tese (Doutorado em Letras e Linguística) - Curso de Pós-graduação em Letras e Linguística, Universidade Federal de Goiás, Goiânia.

ECO, Umberto. Obra Aberta. São Paulo: Perspectiva, 1976.

Os limites da interpretação. São Paulo: Perspectiva, zoro.

Lector in fabula. 2. ed. São Paulo: Perspectiva, 2orza.

Entre autor e texto. In: ECO, Umberto. Interpretação e Superinterpretação. São Paulo: Martins Fontes, 2or2b.

ISER, Wolfgang. $\mathrm{O}$ ato de leitura: uma teoria do efeito estético. Tradução: Johannes Kretschmer.

São Paulo: Ed. 34, 1996, v. I.

AUSS, Hans Robert. O prazer estético e as Experiências Fundamentais da Poiesis, Aesthesis e Katharsis. In: LIMA, Luis (org.). A literatura e o leitor - textos de Estética da Recepção. Rio de Janeiro: Paz e Terra, 1979 .

JIMENEZ, Marc. O que é estética? Tradução Fulvia M. L. Moretto. São Leopoldo: Editora Unisinos, 2004. (Coleção Focus - 3)

LEMINSKI, Paulo. Polonaises. Curitiba: Edição do Autor, 1980. Toda Poesia. São Paulo: Companhia das Letras, 2013.

MELO NETO, João Cabral. A educação pela pedra. Rio de Janeiro: Objetiva, 2008.

MONEGAL, Emir Rodríguez. Borges: uma poética da leitura. São Paulo: Perspectiva, 1980.

OLIVEIRA, Ângelo B. L. de. Estética da Recepção e Cânon. In: Cadernos do IL. Porto Alegre, n. 39, dezembro de 2009. p. II5-120. Disponível em: 〈http://www.seer.ufrgs.br/cadernosdoil〉. Acesso em: 21 mar. 2019. 
PAZ, Octávio. O arco e a lira. São Paulo: Cosac Naify, 2012.

PIGNATARI, Décio. Semiótica \& Literatura. 3. ed. São Paulo: Cultrix, 1974

SALOMÃO, Waly. Tarifa de embarque. Rio de Janeiro: Rocco, 2000.

SANTOS, Boaventura de Souza. Modernidade, identidade e a cultura de fronteira. Tempo Social; Rev. Sociol. USP, S. Paulo, 5(I-2): 31-52, 1993 (editado em nov. 1994).

SANTOS, Márcia Regina Santos. O Leitor-modelo em Umberto Eco. Fragmenta; Revista Científica UNIT, Aracaju, 4: 63-74, 1999.

STAIGER, Emil. Conceitos fundamentais de poética. 3. ed. Tradução Delestre Aída Galeão. Rio de Janeiro: Tempo Brasileiro, 1997. 